\title{
PRÁTICAS EDUCATIVAS EM GRUPO COM UMA TECNOLOGIA SÓCIO-EDUCATIVA: VIVÊNCIAS NA ILHA DE CARATATEUA, BELÉM
}

Educational practices in group with a partner-educational technology: Existences in the Caratateua Island, Belém - Brazil

Prácticas educativas en el grupo con una tecnología socio-educativa: Viviencias en la Isla de Caratateua, Belém - Brasil

Elizabeth Teixeira

\begin{abstract}
Resumo
0 objetivo deste relato de experiência é socializar uma vivência em um projeto de extensão (Projeto Quartas Saudáveis), apoiado pela Universidade do Estado do Pará, desenvolvido no espaço do Instituto Saber Ser Amazônia Ribeirinha, com práticas educativas em grupo e com uma tecnologia sócio-educativa numa perspectiva freireana, com mulheres da ilha de Caratateua, Belém, PA, e apontar a necessidade de os (as) enfermeiros (as) ousarem na prática educativa, descobrindo as riquezas dos trabalhos com grupos em que se desenvolvem e/ou se aplicam tecnologias leves para produzir saúde. Destacam-se alguns pressupostos que orientam o projeto, a vivência da equipe com a Dinâmica Entre Nós, uma tecnologia sócio-educativa em construção, bem como reflexões sobre a vivência a partir de algumas falas das participantes.
\end{abstract}

Palavras-chave: Enfermagem. Prática de Grupo. Educação em Saúde.

\begin{abstract}
The objective of this experience report is to socialize an existence in an extension project (Project Healthy Wednesdays), supported by the University of the State of Pará (Brazil), developed in the Amazonian Riverside Known Being Institute, with educational practices in group and with a social and educational technology in a Freire's perspective with the women of the Caratateua Island, Belém - Pará Brazil, and to show the necessities of the nurses to dare in the educational practical, discovering the wealthy of the group work where is developed and/or is applied light technologies to produce health. Are stand out some presupposed that guide the project, the existence of the team with the Dynamics Among Us, a social-educational technology in construction, as well as reflections about the existence starting from some speeches of the participants.
\end{abstract}

\section{Resumen}

El objetivo de este informe de experiencia es socializar una vivencia en un proyecto de extensión (Proyecto Miércoles Saludables), apoyándose en la Universidad del Estado de Pará (Brasil), desarrollado en el espacio del Instituto Saber Ser Amazónica Ribera, con prácticas educativas en grupo y con una tecnología socio-educativa en una perspectiva de Freire con mujeres de la Isla de Caratateua, Belém, Pará, Brasil y apuntar la necesidad de los (as) enfermeros (as) en la práctica educativa, descubriendo las riquezas de los trabajos con grupos en que se desarrollan y/o se aplican tecnologías leves para producir salud. Destacase algunos presupuestos que guían el proyecto, la vivencia del equipo con la Dinámica Entre Nosotros, una tecnología socioeducativa en construcción, así como las reflexiones sobre la vivencia desde algunos discursos de las participantes.
Keywords:

Nursing. Group Practice. Health Education.
Palabras clave:

Enfermería. Práctica de Grupo. Educación en Salud. 


\section{INTRODUÇÃO}

Nos dias atuais, em que as certezas se esvaem, tudo se move e se desloca, e em que nada é certo, procuramos por grupos as quais pertencer, para nos apoiar. As "comunidadescabide" emergem, nesse contexto, pois com as vulnerabilidades das identidades individuais, busca-se pendurar seus medos e ansiedades individualmente experimentados e, depois disso, realizar os ritos de exorcismo em companhia de outros indivíduos também assustados e ansiosos ${ }^{1: 21}$

Nenhum conjunto ou agregado de indivíduos será uma comunidade se não for tecido de histórias de vida/biografias compartilhadas; esse tecido é constituído de fios intersubjetivos ou juízos subjetivos embora o fato de que eles sejam tecidos juntos empreste a esses juízos um toque de objetividade $e^{1: 62}$. Dentre os modelos de comunidade, destaca-se a comunidade estética e a ética. Na primeira, os laços são mais provisórios e frouxos, descartáveis e pouco duradouros. Na segunda, assumese compromisso de longo prazo, apontando segurança, proteção e certeza, um verdadeiro compartilhamento fraterno. Nesse sentido, tem uma durabilidade prevista (e às vezes institucionalmente garantida).

0 tipo de entendimento em que a comunidade se pauta é o ponto de partida de toda união, é um sentimento recíproco e vinculante [...], é graças a esse entendimento que na comunidade as pessoas permanecem essencialmente unidas a despeito de todos os fatores que as separam ${ }^{1: 15-6}$. Tal pertencimento, além de favorecer o viver no seu sentido mais amplo, também é mediador de processos de aprendizagem.

Para aprender um saber, o indivíduo precisa fazer parte, estar entre, com e em uma comunidade-aprendente: a unidade da aprendizagem não é cada pessoa tomada individualmente. Ela é cada equipe, cada grupo-dialogante no momento em que algum conhecimento é vivido como uma experiência ativa de ensino-aprendizagem ${ }^{2: 100}$. 0 outro / outra influi, colabora e participa do aprender, o verdadeiro "outro (a) coletivo", interativo, social e cultural. Todos, assim, vão aprendendo conhecimentos, ampliando compreensões e alargando sentimentos.

Considerando o atual contexto que suscita o viver / conviver em comunidade, práticas educativas em grupo, bem como tecnologias sócio-educativas (aqui representando as tecnologias leves), emergem como possibilidades para intensificar tais processos e fornecer subsídios para educarcuidar para a autonomia e a emancipação.

Este relato tem como objetivos: socializar uma vivência em um projeto de extensão, Projeto Quartas Saudáveis (PQS), desenvolvido com práticas educativas em grupo e com uma tecnologia sócio-educativa com mulheres da ilha de Caratateua, Belém/PA, e apontar a necessidade de os (as) enfermeiros (as) ousarem na prática educativa, descobrindo as riquezas dos trabalhos com grupos em que se desenvolvem e/ou se aplicam tecnologias leves para produzir saúde.

\section{UM OLHAR ATENTO PARA ALGUNS PRESSUPOSTOS}

A literatura sobre os grupos aponta algumas questões interessantes para introduzir o debate. Destaca-se a natureza gregária do homem para iniciar qualquer discussão sobre a relevância dos estudos e práticas em/um grupo; situa-se 0 surgimento na Grécia antiga; ressalta-se o papel social que desempenham; sinaliza-se uma polissemia conceitual, mas, na prática, os grupos têm existido à revelia da carência de uma maior precisão conceitual ${ }^{3}$.

Numa primeira fase, os grupos passaram a ser utilizados com finalidades estritamente terapêuticas. Numa segunda, sob influência dos trabalhos de Kurt Lewin, na década de 30 (século $X X$ ), passaram a se voltar para o contexto educacional, o que aqui nos interessa debater.

A diversidade de possibilidades é hoje notória e é nesse sentido que as atividades grupais vêm sendo inseridas no trabalho da área da saúde. Na nossa experiência, optamos por desenvolver em/com um grupo de mulheres mudanças de comportamentos cuidativos no que tange a saúde e 0 ambiente, com ênfase na ressignificação das práticas vividas e saberes produzidos num continuum movimento em torno de conhecimentos e relacionamentos. Apostamos na produção de travessias de saberes e redes de afeto exatamente para operar as mudanças de comportamentos cuidativos.

Para a mudança acontecer é preciso ocorrer aprendizagem significativa, que possibilita a aquisição de conhecimentos e informações. 0 aprender em/com um grupo é um movimento permanente que depende da convivência e da aderência de seus membros bem como da consistência e da fluência de seus mediadores/coordenadores. A nosso ver, os grupos emergem como verdadeiras estratégias para produzir o cuidar em saúde.

Destaca-se que a formação de grupos sociais em saúde é uma forma de trabalho vivo em ato com dimensões tecnológicas e, portanto, uma das estratégias para produzir saúde [...] os pequenos grupos de convergência são como um método de desenvolvimento de tecnologias na enfermagem ${ }^{4: 26}$.

Constatamos, nesse sentido, que as práticas e atividades em grupo são cada vez mais constantes no cotidiano da enfermagem, mas muitas vezes as mesmas são desenvolvidas de forma "automática". Nesse sentido, é válido enfatizar que existem condições e aspectos estruturais de funcionamento que precisam ser "bem pensados" para que as atividades desenvolvidas no grupo obtenham êxito.

É necessário, para esse bom andamento e progresso das atividades grupais, conhecer e ouvir cada um que compõe 0 grupo, pois a partir de suas necessidades poderemos avaliar não só as dificuldades, mas achar sua verdadeira identidade e potencialidade. Nesse âmbito, perceber o grupo em sua totalidade ajuda a traçar seus verdadeiros objetivos.

Sobre a Enfermagem e os grupos, identificam-se algumas razões que levam os profissionais de enfermagem ao trabalho grupal como a procura de uma alternativa para atender pessoas, opondo-se principalmente a um cuidado tradicional que privilegia 0 aspecto curativo e o atendimento das necessidades e/ou circunstâncias de alguns serviços, como ambulatórios e centros de saúde.

No grupo de convivência, compartilham-se saberes e afetos bem como experiências e vivências que levam à profunda reflexão. Esse tipo de grupo tem como objetivos formar uma rede de suporte social; buscar autonomia de seus integrantes; 
ampliar a criatividade; tornar oportuna a livre expressão dos participantes sobre suas emoções e seus conhecimentos: ${ }^{5: 106}$. Podemos dizer que todos os grupos têm, ao mesmo tempo, um jeito de ser próprio (uma singularidade) e um pertencimento social pelo qual se fazem similares a outros grupos ${ }^{6: 95}$. Há que se considerar a dialética do grupo, pois nele convergem duas dinâmicas, uma interna e outra externa, que ao mesmo tempo os tornam singulares e plurais, e tais dinâmicas possuem um caráter diversificado que precisa ser respeitado.

A modalidade sócio-educativa objetiva aumentar o nível de reflexão e conscientização das participantes. Nesse tipo de grupo, as novas informações, o questionamento de mitos e preconceitos, a possibilidade de tirar dúvidas representam elementos importantes na mudança das representações que as pessoas fazem das problemáticas de saúde / doença ${ }^{6: 112}$.

Com base nesse primeiro pressuposto, acreditamos que práticas educativas em grupo precisam ser estimuladas e/ou fortalecidas para a manutenção e/ou promoção da saúde e da qualidade de vida.

Em busca de outros pressupostos para subsidiar nosso trabalho, passamos a refletir sobre a concepção de trabalho em saúde e suas tecnologias. Considera-se o trabalho uma atividade que tem como essência alterar o estado natural dos materiais existentes no meio ambiente para serem melhor utilizados. 0 homem, através do seu trabalho, relaciona-se com outros homens e é transformado por essas relações sociais e por outras determinações que ocorrem nesse processo ${ }^{7}$.

Afirma-se que, no trabalho em saúde, o produto final não se restringe a uma mercadoria, mas ao atendimento às necessidades do homem, as quais não são naturais, mas histórica e socialmente determinadas. 0 trabalho em saúde, nessa perspectiva, produz atos de saúde que têm a capacidade de intervir em diversas problemáticas, modificando-as e produzindo como resultado satisfação de uma necessidade/ direito do usuário. Nesse processo, ocorre efetivamente produção de saúde. Esse trabalho é centrado no trabalho vivo em ato e não pode ser capturado na lógica do trabalho morto, expresso somente nos equipamentos/máquinas (tecnologia dura) e nos saberes estruturados (tecnologia leve-dura), pois no campo das intervenções assistenciais há abordagem assistencial de um trabalhador de saúde junto a um usuário/ cidadão, em um processo de relações, que envolve tecnologia de relações (tecnologia leve), de encontros de subjetividades, de produção de vínculo, autonomização (aqui definida como a capacidade do indivíduo de governar o modo de conduzir a sua própria vida) e acolhimento ${ }^{7: 40}$.

A terminologia "tecnologias leves" ${ }^{8}$ refere-se a um tipo de tecnologia que se torna relevante na medida em que se discute a necessidade de construir um outro modelo de atenção em saúde que explore positivamente a capacidade cuidadora do conjunto de trabalhadores de saúde para a defesa da vida. Nesse sentido, as tecnologias leves aproximam-se de atitudes relacionais intersubjetivas de acolhimento, escuta, estabelecimento e articulação de redes de conversas, vínculos, saberes e afetos. Só um modelo assistencial que produza modalidades tecnológicas de assistência, na base do sistema de saúde, comandadas pelo universo das tecnologias leves e que tenham abrangência individual e coletiva, é que pode responder a esta situação, e isto implica em uma decisão política clara, pelos gestores do setor saúde, em investir na qualificação clínica das redes básicas de serviços, ao mesmo tempo em que se aposte na produção de intervenções sobre os fatores de riscos coletivos de adoecer. Só assim é possível construir um modelo assistencial com mais qualidade e mais barato, que respeite os direitos dos cidadãos na saúde, e que tenha a abrangência das ações individuais e coletivas ${ }^{8: 13}$.

As tecnologias leves configuram-se como dispositivos para educar-cuidar em saúde na medida em que são tecnologias contra-hegemônicas, ou seja, em vez de ser centradas em procedimentos, são centradas em relacionamentos. Ao não priorizar as ferramentas-máquinas, permite potencializar as abordagens-dinâmicas, em que os sujeitos se encontram, atuam entre si e operam um jogo de expectativas e produções em alguns momentos: momentos de falas, escutas e interpretações, nos quais há a produção de uma acolhida das intenções que estas pessoas colocam neste encontro; momentos de cumplicidades, nos quais há a produção de uma responsabilização em torno do problema que vai ser enfrentado; momentos de confiabilidade e esperança, nos quais se produzem relações de vínculo e aceitação.

Com base nesse segundo pressuposto, acreditamos que programas educativos em grupo podem ser estimulados e/ou fortalecidos por tecnologias leves para a manutenção e/ou promoção da saúde e da qualidade de vida.

\section{UMA VIVÊNCIA EM GRUPO COM UMA TECNOLOGIA SÓCIO-EDUCATIVA}

Desde 2003 a autora coordena e realiza, com uma equipe multidisciplinar (acadêmicos e profissionais de enfermagem e pedagogia), práticas educativas em saúde e ambiente com/ entre um grupo de mulheres (cerca de 50), participantes de um Projeto de Extensão (PQS), da Universidade do Estado do Pará (UEPA), desenvolvido no espaço de uma ONG localizada na llha de Caratateua, em Belém, PA. Para fortalecer a caminhada, a equipe se aproximou e vem se apropriando dos pressupostos destacados anteriormente para subsidiar 0 processo de (re) pensar o cuidar-educar na perspectiva da educação popular em saúde ${ }^{9}$, com vistas à produção da saúde. Buscar a ressignificação de tais pressupostos para torná-los visíveis foi o nosso primeiro objetivo.

Para dar conta dos temas geradores demandados pelo grupo de mulheres e atender os pressupostos escolhidos pela equipe para nortear o PQS, fomos desenvolvendo, no percurso (2003/2006), uma tecnologia sócio-educativa que passamos a denominar "Dinâmica Entre Nós". Fomos tecendo, com os fios teóricos adotados, uma tecnologia de cuidado educativo singular, organizada em quatro momentos de ação, integrados e relacionados entre si, que foram sendo aprimorados nos múltiplos encontros em grupo. 0 específico da discussão de grupo são as opiniões e os valores expressos pelos participantes que são de "inegável importância para se tratar das questões da saúde sob o ângulo social” 10:129. 
Não partimos de um modelo para a prática, mas exatamente do contrário. Ao longo do processo, fomos criando um conjunto de atividades que convergiam em uma mesma seqüência de passos, para possibilitar a interação e o diálogo entre as mulheres e nós; para viabilizar diferentes vivências educativas com os temas geradores entre as mulheres e nós; para facilitar a expressão das experiências cotidianas relacionadas com o cuidado e autocuidado entre as mulheres e nós; enfim, para favorecer e fortalecer os vínculos e afetos entre as mulheres e nós.

A Dinâmica Entre Nós, ainda em construção e validação pela equipe do $P Q S$, vem favorecendo o diálogo na perspectiva freireana, pois se aproxima do sentido dos círculos de cultura ${ }^{11}$ que promovem e possibilitam o que entendemos por travessias de saberes com e entre afetos. A tecnologia está pautada em quatro momentos: MOMENTO DE APREENSÃO (M1): Quando EM GRUPO apresentam-se questões para discussão formuladas pelo próprio grupo ou equipe. MOMENTO DE EXPRESSÃO (2): Quando 0 GRUPO expõe o que apreendeu da discussão inicial sobre o tema. MOMENTO DE APRECIAÇÃO (3): Quando NO GRUPO emerge o debate mediado pelo facilitador. MOMENTO DE RECONSTRUÇÃO (4): Quando ENTRE NÓS compõe-se uma síntese, mesmo que provisória, sobre o tema em discussão.

A tecnologia vem sendo usada nos encontros em grupo, e os temas tratados são relacionados tanto à saúde como ao ambiente. A equipe construiu um instrumento, denominado Ata do PQS, para registrar os momentos, dando ênfase às unidades de fala das participantes.

\section{REFLEXÕES SOBRE A VIVÊNCIA: VOZES DOS SUJ EITOS E NOSSO SENTIR}

Em 2005 e 2006 passamos a analisar os registros e declarações das participantes do PQS. Algumas dessas declarações apontam que a experiência em grupo com a tecnologia sócioeducativa Dinâmica Entre Nós, contribui tanto para o processo de aprender como o de conviver, tanto para dimensões cognitivas como afetivas, como podemos constatar a seguir:

Ensinam bem explicado, é totalmente diferente. As explicações, as dinâmicas, brincadeiras, porque elas usam a linguagem de gente. 0 que facilita são as perguntas, é legal essa troca de perguntas. Tem apostilas, o conjunto faz a gente pensar mais rápido, o pessoal explicando, a gente entende melhor, trabalhar em grupo é muito bom, as figuras mostrando a realidade, depoimentos, sempre há uma resposta clara. Aquele calor humano, a acolhida que vocês têm com a gente faz a gente se sentir bem, a gente pergunta até entender, porque a gente não tem que sair de lá com dúvida (M10).

No registro em destaque, manifesta-se o círculo de cultura que permite o diálogo eu-tu, a existência no grupo e o aprender com/entre nós. Com efeito, a existência se dá quando o que existe está situado dentro, entre e em algum tipo de relacionamento com.

A Teia da Existência se constitui nas, entre as e através das relações de troca que a cada momento estabelecem, transformam e recriam tudo o que envolve a realidade da vida 2:21. Podemos afirmar que existimos em função das trocas que produzimos em cada encontro educativo, em cada celebração, em cada entre nós.

0 ofício de educador (a) numa perspectiva freireana viabiliza sentimentos mútuos, emoções e acolhimento. Amamos e nos amamos reciprocamente em cada encontro, em cada Quarta Saudável. Esse "amor coletivo" nos envolve com e entre saberes, prazeres, dizeres, interações significativas que geram confiança e produzem vínculos. [...] A confiança, nesse sentido, é fundamental para um casulo protetor que monta guarda em torno do eu em suas relações com a realidade cotidiana ${ }^{1: 127}$. Para Humberto Maturana a relação fundadora da experiência interativa é o amor. É preciso sentir uma troca amorosa para, efetivamente, suportar conviver. Viver à margem do amor não é ruim, é insuportável 1:131.

Destaca-se o permanente inacabamento do ser, que se descobre aprendente e fica feliz por isso. Nós, juntos, em grupo, estamos intertrocando saberes e afetos, sensibilidades e significados, sensações e sociabilidades. Mutuamente nos ensinamos e aprendemos. Há sempre presente nas práticas educativas do PQS, uma dimensão de ser ensinante que se destaca como condição para uma outra de ser aprendente. E é com diálogo que esse continuum se dá plenamente. Reforça-se a idéia de "círculos de diálogos" a cada encontro, para pensar o saber enquanto fluido e fluxo de um movimento circular e dialógico; [...] estamos destinados a aprender a saber como uma atividade perene ao longo da vida, dentro e fora das estruturas e dos cenários da educação formal:1:45. Nesse sentido, o saber não tem lugar fixo, ator principal e/ou língua oficial, mas sim é um entre - lugar, entre e com todos, e que se traduz entre e com múltiplos signos e símbolos.

Parte-se da compreensão de que os trabalhos em grupo favorecem travessias de saberes com e entre afetos e as tecnologias sócio-educativas numa perspectiva Freireana são meios que possibilitam produzir saberes e saúde. Acredita-se que as práticas educativas pautadas nos pressupostos aqui destacados poderão propiciar ganhos cognitivos e vínculos afetivos entre educadores de saúde e usuários.

\section{CONSIDERAÇÕES FINAIS}

Os grupos são dispositivos de mudança, ou seja, instrumentos que possibilitam aos seus participantes mudanças de idéias e práticas. Não podemos deixar de crer que tais mudanças trazem um impacto na cultura local e têm um papel multiplicador/irradiador no contexto mais global. Essa dialética entre a dinâmica interna e externa é que torna 0 grupo uma estratégia para produzir saúde.

Assim, é preciso todos os tipos de tecnologias (duras, leveduras, leves), o que vai configurar toda a complexidade das ações e produção de saúde. É preciso ampliar as dimensões do fazer e, com isso, do saber ser dos profissionais de saúde.

Queremos destacar o reconhecimento social das mulheres como sujeitos históricos que cuidam, e nesse sentido, nossa experiência com um grupo de mulheres da ilha nos tem mostrado que elas atendem ao "chamado" dos profissionais e se 
interessam em participar de programas educativos, voltados para o cuidar cotidiano de saúde ${ }^{12}$. 0 maior desafio, a nosso ver, é promover nesses programas conhecimentos e relacionamentos capazes de produzir saberes e afetos.

Cada vez mais necessitamos nos sentir dentro/entre, cada vez mais precisamos pertencer a e viver em comunidade. 0 processo de aprender (e ensinar) caminha nessa mesma direção. Aprendemos mais dentro/entre comunidades aprendentes. Faz-se, assim, essencial no trabalho em saúde articular tais pressupostos.

\section{Referências}

1. Bauman Z. Comunidade: a busca por segurança no mundo atual. Rio de Janeiro(RJ): Zahar; 2003.

2. Brandão CR. A canção das sete cores: educando para a paz. São Paulo(SP): Contexto, 2005.

3 . Munari DB, Rodrigues ARF. Enfermagem e grupos. Goiânia(GO): AB; 1997.

4. Schier J. Tecnologia de educação em saúde: 0 Grupo Aqui e Agora. Porto Alegre(RS): Sulina; 2004.

5. Silva DGV et al. Grupos como possibilidade para desenvolver educação em saúde. Texto Contexto Enferm 2003 jan/mar;12(1): 97-113.

6. Afonso $L$ et al. Oficinas em dinâmica de grupo na área da saúde. Belo Horizonte(MG): Campo Social; 2003.

7. Zerbetto SR, Pereira MAO. 0 trabalho do profissional de nível médio de enfermagem nos novos dispositivos de atenção em saúde mental. Rev Latino-Am Enfermagem 2005 jan. /fev; 13(1): 38-45.
Concluindo, vários desafios ainda precisam ser vencidos para o fortalecimento do cuidar-educar para produzir saúde com tecnologias leves entre os (as) enfermeiros (as). Nós, profissionais de saúde, precisamos ampliar tanto as práticas cuidativas como as educativas e, com isso, alargar nosso pensar/ fazer/conviver no sistema. A nosso ver o cuidado solitário precisa ser substituído pelo solidário, em que nem eu, nem tu, mas NÓs participamos, aprendemos, ensinamos entre Nós; em que produzimos saúde e realizamos travessias.

8. Merhy EE. A perda da dimensão cuidadora na produção da saúde: uma discussão do modelo assistencial e da intervenção no seu modo de trabalhar a assistência. Disponível em: www.hc.ufmg.br/gids/perda/doc.

9. Vasconcelos EM. Educação popular e a atenção à saúde da família. $2^{a}$ ed. São Paulo(SP): Hucitec; 2001.

10. Minayo MCS. 0 desafio do conhecimento. Paulo(SP): Hucitec; 1992. 11. Freire P. Pedagogia da autonomia. Paulo(SP): Cortez; 1996.

12. Teixeira E. Travessias, redes e nós: complexidade do cuidar cotidiano de saúde entre ribeirinhos. Esc Anna Nery Rev Enferm. 2000 ago; 4(2): 269-78.

\section{Sobre a Autora}

\section{Elizabeth Teixeira}

Prof $^{a} \mathrm{Dr}^{\mathrm{a}}$ do Curso de Graduação em Enfermagem e do Programa de Mestrado em Educação da Universidade do Estado do Pará. Doutora em Ciências Sócio-Ambientais (UFPA). Pós-Doutorado em Sociologia (Universidade de Coimbra). Pesquisadora do Núcleo de Educação Popular Paulo Freire. e-mail: etfelippe@terra.com.br 